\title{
CONTRIBUIÇÕES DA TEORIA INSTITUCIONAL PARA A ANÁLISE DA GESTÃo DE ESCOLAS: UM ESTUDO DE CASO DE ESCOLA PÚBLICA BRASILEIRA BEM SUCEDIDA NOS ÍNDICES DE DESEMPENHO DA EDUCAÇÃO BÁSICA
}

\author{
Ângela França Versiani* \\ versiani@pucminas.br \\ Sérgio Fernando Loureiro Rezende* \\ srezende@pucminas.br \\ Antônio Carlos Pereira** \\ carlaopereira13@gmail.com
}

*Pontifícia Universidade Católica de Minas Gerais - Belo Horizonte, MG/ Brasil

**Secretaria do Estado de Educação de Minas Gerais - Belo Horizonte, MG/ Brasil

http://dx.doi.org/10.1590/1413-2311.0312015.57041

Recebido em 11/07/2015

Aprovado em 30/05/2016

Disponibilizado em 06/06/2016

Avaliado pelo sistema "double blind review"

Revista Eletrônica de Administração

Editora-chefe: Aurora Zen

ISSN 1413-2311 (versão "on line")

Editada pela Escola de Administração da Universidade Federal do Rio Grande do Sul.

Periodicidade: Quadrimestral

Sistema requerido: Adobe Acrobat Reader

\section{RESUMO}

O presente artigo discute como a teoria institucional auxilia no entendimento da gestão de escolas. Ao sustentar o argumento de que a gestão educacional é decorrente de processos de institucionalização, realizou-se uma pesquisa qualitativa em uma escola de rede pública municipal que tem alcançado resultados positivos de desempenho escolar acima da média do Brasil em avaliações governamentais sobre qualidade da educação. Essa pesquisa teve por objetivo identificar se e como foi institucionalizado um padrão específico de gestão e os valores que o sustentava. $\mathrm{Na}$ análise dos dados, constatou-se a institucionalização de um modelo de gestão educacional desenvolvido ao longo do período de 1971 a 2010. Tal modelo denominado de proativo sustenta os valores que exaltam o aluno, a confiança nos relacionamentos e as práticas de participação no ambiente escolar. A principal contribuição do estudo foi o de identificar os aspectos simbólicos que guiam a lógica institucional das escolas públicas da educação básica.

Palavras-Chave: teoria institucional; processos institucionais; organizações educacionais; gestão escolar; gestão educacional; educação básica. 


\title{
THE EDUCATIONAL MANAGEMENT FROM INSTITUTIONAL PERSPECTIVE: \\ A CASE STUDY OF A BRAZILIAN PUBLIC SUCCESSFUL SCHOOL IN \\ ELEMENTARY EDUCATION
}

\begin{abstract}
This article shows how institutional theory collaborates to better our understanding about the management schools. We hold an argument that educational management is based on institutional processes. In such discussion, we have done a qualitative research in a school that has been successful in learning as well as it has achieved high scores in governmental assessments of quality in education. In particular, we seek to identify whether and how a specific pattern of management and values emerge during the period between 1971 and 2010 . In the data analysis, we unveiled an educational management model, which was identified as proactive. Their core values were enhancement of student, trust in relationships and practices of participation in the school. The main contribution of this study, in turn, enabled us to identify the symbolic aspects spread in the organizational field of public schools in elementary education.
\end{abstract}

Keywords: institutional theory, institutional processes; educational organizations, school management, educational management, elementary education.

\section{LA GESTIÓN DE LAS ESCUELAS EN LA LUZ DE LA TEORÍA INSTITUCIONAL: UN ESTUDIO DE CASO DE LA ESCUELA PÚBLICA DE BRASIL CON ÉXITO EN LOS ÍNDICES DE RENDIMIENTO DE EDUCACIÓN BÁSICA}

\begin{abstract}
RESUMEN
Este artículo tiene como objetivo discutir la gestión de las escuelas de educación básica en Brasil. Para esta discusión utilizamos el marco teórico de la teoría institucional mediante la realización de un estudio cualitativo en una escuela del sistema público de ha logrado resultados positivos en el aprendizaje escolar por encima del promedio para Brasil en los exámenes del gobierno de la calidad de la educación. Esta investigación tuvo como objetivo identificar si y cómo se institucionaliza un patrón específico de la gestión y los valores que lo sostenían. En el análisis de datos se encontró la institucionalización de un modelo de gestión educativa desarrollada en el período de 1971 a 2010. Este modelo se llama de forma proactiva apoya los valores que exaltan el estudiante, la confianza en las relaciones y la participación en prácticas ambientales colegio. La principal contribución de este estudio fue identificar los aspectos simbólicos que guían la lógica institucional de las escuelas públicas de educación básica.
\end{abstract}

Palabras clave: institucional teoria; procesos institucionales; organizaciones educativas; la gestión escolar; gestión de la educación; educación primaria.

REAd | Porto Alegre - Edição 83 - Nº 1 - Janeiro/Abril 2016 - p. 193-224 
Ângela França Versiani, Sérgio Fernando Loureiro Rezende \& Antônio Carlos Pereira

\section{INTRODUÇÃO}

A teoria institucional é uma perspectiva de análise que ressalta os aspectos culturais do ambiente como determinantes do comportamento das organizações, os quais restringem e as submetem a normas de ação (Scott, 2001; Reed, 1999). Tal perspectiva é reconhecida nos estudos organizacionais como conceitualmente sólida (Meyer; Höllerer, 2014), embora existam diversas oportunidades de pesquisa para suprir lacunas antigas ainda existentes na literatura (Suddabay, 2010; Greenwood et al., 2008). Dentre essas lacunas está a afirmação de Tolbert e Zucker (1999) de que os processos de institucionalização não foram suficientemente pesquisados. Essa constatação tem sido reforçada, mais recentemente, pelas reflexões de Zilber (2008). Esse autor afirma que, embora a perspectiva institucional tenha desenvolvido sua teoria alicerçando-a no papel que os significados exercem na conformação das estruturas organizacionais, as pesquisas empíricas não lhes deram o devido realce. Zilber (2008) constata a tendência dos estudos de focar a legitimação de uma estrutura ou prática organizacional desprovendo-se da indagação sobre os significados e ou processos culturais envolvidos nessa legitimação.

Essa tendência é recorrente nos poucos estudos sobre processos institucionais de escolas (Meyer; Rowan, 2006), mesmo naqueles que discutem o aparecimento de novas estruturas educacionais (Rowan,1982), a natureza dos sistemas educacionais e suas reformas (Fusarelli,2002), a conduta de organizações escolares (Meyer; Rowan, 2006), bem como os efeitos da escola nos resultados dos alunos (Berends, 2015). Salienta-se que os mecanismos dos processos institucionais que envolvem a gestão das escolas têm sido negligenciados nessa agenda de pesquisa (Fast, 2016, Bidwell, 2006). Acredita-se que a escassez desses estudos seja decorrente da expansão global da educação que pressiona para uma uniformidade sobre o que as nações e as escolas deveriam ser. Como consequência as pesquisas sobre processos de institucionalização, envolvendo os aspectos culturais têm caminhado lentamente como permanecem vagas no que se referem aos processos institucionais da gestão educacional (Meyer; Rowan, 2006). Visando dirimir essa lacuna fortalecem-se as vozes em prol de estudos que ampliem a base empírica de pesquisas sobre processos de institucionalização (Fast, 2016), e, ao fazê-lo resgate-se a dinâmica e o papel dos valores e significados desses processos (Hatch, 2012; Kraatz; Ventresca ; Deng, 2012).

Essa sugestão é especialmente relevante para a agenda de pesquisa brasileira. Isto porque, pesquisas dedicadas à análise dos processos de institucionalização são muito 
CONTRIBUIÇÕES DA TEORIA INSTITUCIONAL PARA A ANÁLISE DA GESTÃO DE ESCOLAS: UM ESTUDO DE CASO DE ESCOLA PÚBLICA BRASILEIRA BEM SUCEDIDA NOS ÍNDICES DE DESEMPENHO DA EDUCAÇÃO BÁSICA

incipientes (Guarido Filho, 2008) principalmente aquelas que tratam da gestão das escolas. Essa constatação foi corroborada em levantamento bibliográfico sobre o estado da arte da literatura em processos de institucionalização, realizado em dezembro de 2014, pelos autores deste artigo, nas bases de dados do banco de teses da CAPES (Coordenação de Aperfeiçoamento de Pessoal de Nível Superior) e nas revistas mais bem classificadas no sistema QUALIS-CAPES. Nesse levantamento, não foram encontrados trabalhos sobre processos de institucionalização em escolas, à exceção dos estudos de Lopes (1999) ou de Schhilckmann, Melo e Alperstedt (2008). Tais estudos possuíram como objeto empírico as escolas da educação superior, em específico, as universidades. Pesquisas sobre processos de institucionalização em escolas da educação básica não foram identificadas, salvo maior engano.

Entretanto, há o reconhecimento da necessidade de se estudar a gestão dessas escolas. Um exemplo de recomendação em prol desses estudos vem do Ministério da Educação (MEC) por meio da CAPES. Essa coordenação tem proposto aos programas de pós-graduação stricto senso, principalmente da área de administração, fomentar pesquisas que possam contribuir com a qualidade da educação básica no país (Capes, 2010). Esse anseio parece ancorar-se nas suposições de especialistas da educação de que a gestão das escolas, também entendida como gestão educacional (Ledesma, 2008; Casassus, 2010) é um dos importantes aspectos que impactam os resultados de desempenho escolar (Menezes Filho, 2007; Abramovay, 2003). Junto a essas suposições, estão presentes os argumentos de que o tratamento da gestão educacional não pode ser igualado ao da gestão de empresas. Alegam-se que as escolas possuem especificidades, enquanto espaço social, diferentes das empresas (Hora, 2007; Martins, 2004).

A despeito da pertinência de tal alegação, não há por parte dos pesquisadores assertivas quanto ao tratamento teórico adequado, quando o objeto de discussão é a gestão educacional. Nesse sentido, as críticas de tratar a gestão das escolas como similar à gestão empresarial se tornam muito mais, reações ideológicas contra o princípio de racionalidade técnica própria da administração, que gera distorções na forma de encarar a escola, do que da apresentação de alternativas teóricas concretas para se abordar tal gestão. Defende-se, neste artigo, que uma solução teórica possível ao tratamento da gestão das escolas pode ser vislumbrada na adoção da teoria institucional para compor um quadro teórico de análise. Essa defesa se embasa tendo em vista os propósitos de tal teoria.

REAd | Porto Alegre - Edição 83 - N 1 - Janeiro/Abril 2016 - p. 193-224 
Ângela França Versiani, Sérgio Fernando Loureiro Rezende \& Antônio Carlos Pereira

A teoria institucional é notadamente reconhecida, nos estudos em organizações, como uma das perspectivas mais profícuas ao tratamento de organizações sensíveis aos valores sociais, como os são as escolas (Scott, 2001; Meyer; Rowan, 1977). É importante salientar que tal perspectiva não busca soluções para os problemas de gestão, educacionais ou de desempenho, mas o seu referencial teórico pode contribuir para o entendimento de como e por que determinadas escolas desenvolvem específicas formas de gestão e as consequências a elas associadas (Burch, 2007; Scott, 2001).

Essa possibilidade de compreensão leva-nos a sustentar a ideia de que a gestão das escolas é decorrente de processos institucionais (Meyer; Rowan, 1983). E, de que, tais processos possuem efeitos sobre a própria escola e a sociedade (Rowan; Denk, 1983). Os valores e normas da sociedade perpassam a constituição da gestão das escolas, ao mesmo tempo em que essa mesma gestão constitui visões que ora afirmam ou questionam tais valores, revertendo-os novamente para a sociedade (Burch, 2007). Nesse sentido, as escolas e a sociedade desenvolvem relações dialéticas que promovem ordens sociais e suas mudanças.

Com esse ponto de vista, propõe-se, discutir por meio de uma pesquisa qualitativa, a gestão de uma escola da educação básica da rede municipal de Belo Horizonte (MG) que tem alcançado desempenho escolar acima da média do Brasil em avaliações governamentais. Essa escola justifica empiricamente a importância deste estudo por ser considerada como um caso de relevância em qualidade de educação no país. O objetivo da pesquisa foi o de identificar se e como foi institucionalizada a gestão educacional da referida escola municipal e os valores que a sustenta. Na análise dos dados pôde-se observar a institucionalização de um padrão de gestão educacional, cujos valores exaltam o aluno, a confiança nos relacionamentos e as práticas de participação no ambiente escolar.

Visando apresentar a conclusão acima, o artigo foi organizado em seis seções incluindo esta introdução. Na segunda seção apresentam-se as contribuições da teoria institucional na análise da gestão das escolas. A lógica da pesquisa é descrita na terceira seção. E os dados são relatados na quarta. Em seguida, na quinta seção, procedem-se a análise e suas conclusões. Finalmente, a sexta seção sintetiza os resultados e aponta sugestões para pesquisas futuras e as limitações do presente estudo.

REAd | Porto Alegre - Edição 83 - N 1 - Janeiro/Abril 2016 - p. 193-224 
CONTRIBUIÇÕES DA TEORIA INSTITUCIONAL PARA A ANÁLISE DA GESTÃO DE ESCOLAS: UM ESTUDO DE CASO DE ESCOLA PÚBLICA BRASILEIRA BEM SUCEDIDA NOS ÍNDICES DE DESEMPENHO DA EDUCAÇÃO BÁSICA

\section{CONTRIbUiÇÕES DA TEORIA INSTITUCIONAL PARA A ANÁlise DA GESTÃO DAS ESCOLAS}

A teoria institucional tem sido identificada nos estudos em gestão como uma perspectiva de análise cuja preocupação está em explicar os efeitos dos valores sociais sobre as organizações (Scherer, 2005; Hatch, 1997; Perrow; 1993). A despeito das variantes em que tal explicação se fundamenta (Greenwood et al., 2008; Fonseca, 2003; Scott, 2001; Dimaggio; Powell, 1991; Selznick, 1996), o seu foco teórico está tradicionalmente alicerçado no diálogo sobre como se desenvolvem os processos institucionais e ocorre a conformidade das organizações ao ambiente (Suddabay, 2010). Esse diálogo remonta às contribuições de Selznick $(1949,1957)$ ao identificar a existência de uma variedade de tipos de organizações classificadas de acordo com a sujeição de sua administração aos valores dos grupos internos e externos.

Organizações são sujeitas à institucionalização, segundo Selznick (1996), quando assumem um conjunto de práticas em torno de valores específicos que lhes conferem uma competência distintiva devido à importância adquirida em relação a outras na sociedade, ou pelo desenvolvimento de uma incapacidade treinada com respaldo na própria sociedade. A importância dos aspectos simbólicos impregnados no ambiente é o aspecto central da institucionalização. Meyer e Rowan (1977) admitem que a institucionalização ocorre porque redes de interação entre organizações veiculam um conjunto de valores tidos como racionais e certos para determinados agregados, pressionando-as adotar específicas políticas, programas, procedimentos administrativos e ou formas de gestão, também denominados de arranjos estruturais. $\mathrm{O}$ atendimento a essas pressões garantem legitimidade às organizações (Scott, 2001; Jepperson, 1991; Meyer; Rowan, 1977), protegendo-as do questionamento em relação a sua conduta (Dimaggio; Powell, 1991).

A busca de legitimidade pode levar a adoção de arranjos estruturais apenas cerimonialmente sem que haja relação com desempenho, gerando como consequência desacoplagens entre atividades de trabalho e os arranjos estruturais adotados (Suddabay, 2010; Scott, 2001; Meyer; Rowan, 1977). Essa situação é especialmente identificada em organizações cujas tecnologias não são claramente definidas e os resultados difíceis de avaliar (Meyer; Rowan, 1977), como por exemplo, as escolas (Dacin; Munir; Tracey, 2010; Schilckmann; Melo; Alperstedt, 2008; Scott, 2001; Lopes, 1999). As características das 
escolas mostram quão dependentes elas são das pressões ambientais, e como desacoplagens lhes são inerentes (Burch, 2007; Weick, 1976; Meyer; Rowan, 1977).

A escola é um espaço de atendimento ao direito educacional dos alunos, uma comunidade educativa, de profissionais (Soares, 2004), que se estrutura em função das diretrizes, normas e políticas de ensino, de um lado, e pelas relações desenvolvidas de ensinoaprendizagem de outro (Casassus, 2002). As escolas são similares aos sistemas frouxamente acoplados (Weick, 1976), expressando uma realidade em que políticas governamentais, professores, diretores, discentes e a comunidade de pais estão de alguma forma conectados, mas os elementos em comum compartilhados são "superficiais" e relativamente independentes uns dos outros. Daí as afirmativas de que as escolas expressam elementos de um sistema imperfeitamente integrado por competência técnica (Scott, 2001; Meyer;Rowan, 1977; Weick, 1976), possuindo metas e objetivos abstratos (Witziers, 2006), assemelhando-as ao que é denominado por Cohen; March e Olsen (1972), de organizações com feições de anarquia organizada.

O reconhecimento da escola, em particular, das escolas públicas da educação básica, objeto deste trabalho, como sistemas de acoplagens frouxas e que seguem as prescrições do ambiente (Fusarelli, 2002) remete a uma concepção na qual, por exemplo, os seus efeitos, dentre eles, a capacidade de propiciar aprendizagem em seu público alvo, não é uma questão estritamente técnica. Essa ideia encontra respaldo nas análises de diferentes autores tais como, Soares (2004), Casassus (2002) ou Witziers (2006). Esses autores sugerem ser a aprendizagem escolar mediada por processos de institucionalização, por exemplo, a institucionalização da gestão escolar, também, denominada de gestão educacional (Ledesma, 2008).

A análise de tal gestão requer que se incorpore um conjunto de críticas dirigidas à teoria institucional e que, uma vez admitidas, aprimoraram sua capacidade de explicação. Tolbert e Zucker (1999) são exemplos de autores que sugeriram desfazer-se de dois exageros conceituais comumente presentes no quadro explicativo da teoria institucional. Primeiro, diminuir a ênfase do determinismo ambiental sobre o comportamento das organizações. E segundo, eliminar a distorção que a ideia de desacoplagens trouxe para as análises. De acordo com esses autores, o determinismo ambiental obscureceu a ideia da institucionalização como processo e resultado simultaneamente. E o exagero na ideia de desacoplagens levou a negligenciar os efeitos da ação exercida pelos membros da organização e suas atividades cotidianas nos processos de institucionalização. Tais críticas mostraram a importância de se

REAd | Porto Alegre - Edição 83 - N 1 - Janeiro/Abril 2016 - p. 193-224 
CONTRIBUIÇÕES DA TEORIA INSTITUCIONAL PARA A ANÁLISE DA GESTÃO DE ESCOLAS: UM ESTUDO DE CASO DE ESCOLA PÚBLICA BRASILEIRA BEM SUCEDIDA NOS ÍNDICES DE DESEMPENHO DA EDUCAÇÃO BÁSICA

resgatar o conceito de agência (Silva; Fonseca; Crubellate, 2010; Battilana, 2006; Reed, 1997) e entender a dialética dos sistemas frouxamente acoplados (Orton; Weick, 1990). Essa compreensão está no reconhecimento de que em tais sistemas algumas ligações persistem e impõem regras aos seus membros, sendo que muitas vezes os significados compartilhados entre os indivíduos constituem a base de acoplamento das ligações (Orton; Weick, 1990). Nesse sentido entender o processo de institucionalização pressupõe abordar as práticas sociais localizadas na organização (Zilber, 2008) a partir da recursividade entre ambiente, agência, estrutura e interpretação (Silva; Fonseca; Crubellate, 2010; Reed, 2005).

O processo de institucionalização compreende os movimentos de habitualização, objetificação e sedimentação (Tolbert; Zucker, 1999). A habitualização é entendida como comportamentos empíricos adotados em relação aos problemas recorrentes. Já a objetificação refere-se à disseminação dos valores veiculados por tais comportamentos. Enquanto a sedimentação é identificada com a perpetuação por longos períodos de tempo de tais valores incrustados em práticas repetidas que formam os arranjos estruturais. A institucionalização, apesar de ser um padrão estável de regras sociais enraizada na sedimentação, não implica um produto exógeno às ações dos indivíduos, mas uma realidade que confronta as regras, e tipificações socialmente aceitas e cristalizadas ao longo do tempo, com os problemas enfrentados cotidianamente. A teoria de estruturação de Giddens (2003) tem sido utilizada no sentido de demarcar o que se denomina de recursividade entre agência e estrutura (Rossoni; Guarido Filho; Coraiola, 2013; Silva; Fonseca; Crubellate, 2010; Reed, 2005).

A recursividade entre agência e estrutura refere-se à produção ou reprodução de um arranjo estrutural específico a partir da imbricação das ações dos agentes sociais e limites impostos pelas molduras de coerção que antecedem e estão presentes no contexto em que ocorrem suas interações. A agência significa, segundo Giddens (2003), que ações de agentes perpetrando-se ao longo do tempo tornam-se práticas sociais ordenadas no tempo e espaço. Tais práticas, ao ganhar status de prescrições duradouras, apresentam propriedades estruturais. Essas propriedades, por sua vez, oferecem recursos simbólicos para reproduzir ou recriar as ações das pessoas em um contínuo fluxo de monitoração reflexiva. A reflexividade dos agentes mediados pelas regras e recursos das propriedades estruturais e pelo seu contexto de interação pressupõe interpretação, vista como "o mecanismo operacional de natureza cognitivo-cultural da recursividade inerente à institucionalização" (Silva; Fonseca; Crubellate, 2010, P.95). Desse modo, significados compartilhados estão presentes ao longo de todo o processo de institucionalização, representando os aspectos ideacionais de um padrão de ações

REAd | Porto Alegre - Edição 83 - N 1 - Janeiro/Abril 2016 - p. 193-224 
que se consolidou ao longo do tempo, veiculando determinados valores. A partir dessa compreensão pode-se desenvolver uma moldura teórica para a análise da institucionalização da gestão educacional (ver figura 1).

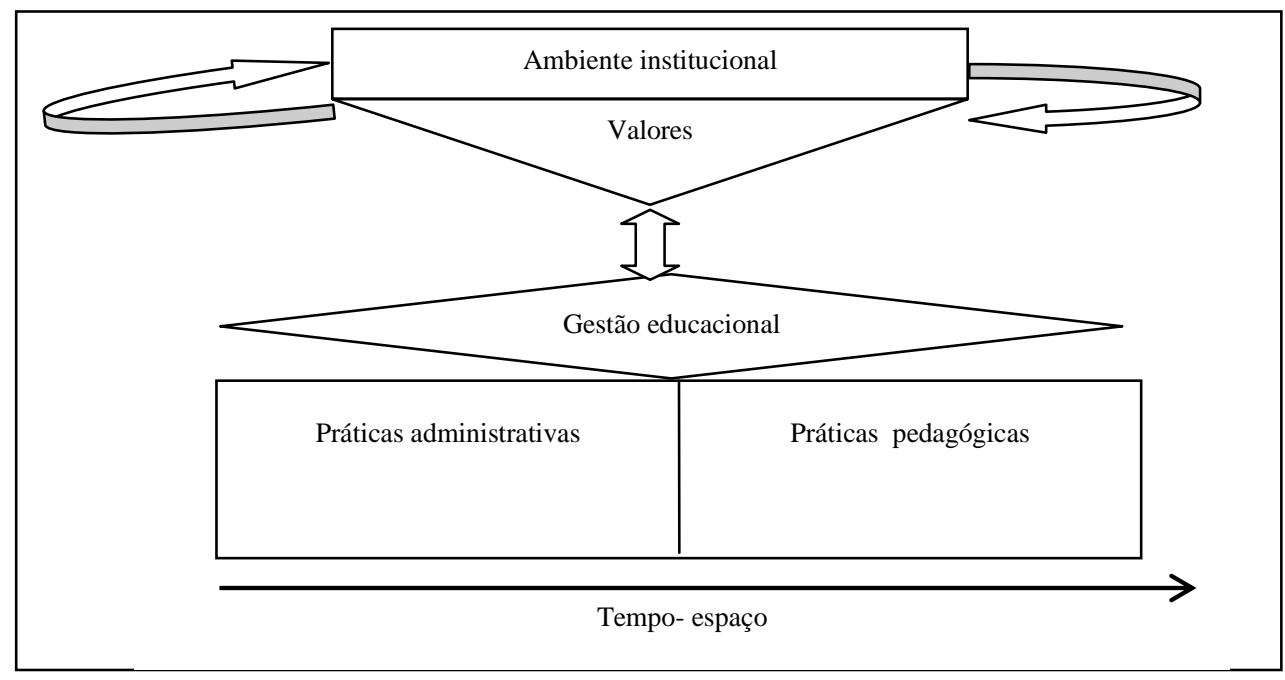

Figura 1 - Elementos da análise da institucionalização da gestão educacional Fonte: Elaborado pelos próprios autores

O ambiente institucional é representado, por exemplo, pelas pressões da esfera pública e das associações profissionais que ditam regras de comportamento e procedimentos a serem adotados na gestão das escolas. Essas pressões implicam valores. Tais regras e procedimentos ao serem adotados são reinterpretados, reformulados ou reforçados no processo de sua adoção. Desse modo, a articulação dos recursos materiais e humanos e os diferentes papéis desempenhados pelos atores no interior da escola desenvolvem um modus operandi próprio de funcionamento que adquire regularidade, permanência e legitimação. O resultado da conformação desses aspectos denomina-se institucionalização da gestão educacional. Em outras palavras, sedimenta-se um padrão de gestão derivado das pressões institucionais transformadas por meio da interpretação intersubjetiva, ou seja, dos valores presentes nas práticas da gestão educacional adotada pelos atores da escola. Tais práticas e valores, repetindo-se ao longo do tempo formam um arranjo estrutural duradouro, ou seja, um modelo de gestão que guia ações futuras.

Cabe destacar que a denominação "modelo de gestão educacional" não diz respeito a uma melhor forma de gerir os recursos da escola, e sim, a adoção de uma estrutura específica de gestão das escolas. Isto é, o "modelo de gestão educacional" refere-se à fase da sedimentação dos processos institucionais. Ao longo do tempo, consolida-se um padrão de ações, significados e interações que articulam as condições materiais e humanas presentes no REAd | Porto Alegre - Edição 83 - N 1 - Janeiro/Abril 2016 - p. 193-224 
CONTRIBUIÇÕES DA TEORIA INSTITUCIONAL PARA A ANÁLISE DA GESTÃO DE ESCOLAS: UM ESTUDO DE CASO DE ESCOLA PÚBLICA BRASILEIRA BEM SUCEDIDA NOS ÍNDICES DE DESEMPENHO DA EDUCAÇÃO BÁSICA

processo educativo (Casassus, 2002). Esse padrão é composto por práticas administrativas responsáveis pela formulação do programa geral da escola e suas relações com a comunidade, e as práticas pedagógicas, compreendendo os modos de realizar a ação educativa, os quais englobam o currículo, os conteúdos e a forma de ensinar (Ledesma, 2008). O modelo de gestão educacional é o resultado das pressões advindas do ambiente institucional por meio da dominação de determinados valores, que veiculam práticas administrativas e pedagógicas consideradas legítimas. No processo de adoção dessas práticas, as mesmas ou são reforçadas por meio de sua utilização ou são reformuladas por reinterpretações gerando outros valores impregnados na solução de problemas educacionais cotidianos. Desse modo, as práticas administrativas e pedagógicas que se efetivam no interior das escolas contribuem para gerar valores que são, em maior ou menor grau, absorvidos pelo ambiente institucional. Em suma, a moldura teórica, aqui proposta, ressalta que o "modelo de gestão educacional" é resultado das pressões e valores do ambiente, bem como daqueles valores que são gestados no interior da escola mediante práticas administrativas e pedagógicas exercidas na comunidade escolar. Assim sendo, conclui-se que o modelo de gestão educacional representa a institucionalização da gestão no nível da escola. Abordar tal institucionalização significa compreender como se constitui o padrão de gestão prevalecente em escolas localizadas em determinados contextos espaços-temporais.

\section{DESENHO METODOLÓGICO DA PESQUISA}

Compreender se e como ocorre à institucionalização da gestão educacional, objetivo deste trabalho, levou à utilização do método qualitativo. Tal método, ao desvendar o ponto de vista das pessoas envolvidas em determinadas situações (Miles; Huberman, 1994), tem sido considerado como adequado para se estudar processos de institucionalização (Barley; Tolbert, 1997), principalmente quando se trata de casos típicos e relevantes sobre determinados assuntos que ainda não foram suficientemente explorados (Einsenhart, 1989), como por exemplo, a gestão das escolas da educação básica.

Assim foi selecionado o caso da Escola Municipal João Pinheiro que representa a unidade de análise da pesquisa. A escolha deste caso se deu em função de sua importância no sistema educacional brasileiro. Esta escola faz parte da rede municipal de ensino de Belo Horizonte (MG) e possui IDEB (Índice de Educação Básica) acima da média brasileira. O IDEB foi instituído, em 2007, pelo MEC (Ministério da Educação e Cultura) e estabelece o 
Ângela França Versiani, Sérgio Fernando Loureiro Rezende \& Antônio Carlos Pereira

desempenho das escolas no que diz respeito à aprovação, reprovação e evasão de alunos, em uma escala que varia de 0 a 10. No período de 2007 a 2013, a Escola Municipal João Pinheiro registrou IDEB acima de 6,0, enquanto o Brasil ficou apresentou o índice entre 4,2 e 5,2. Cabe registrar que a pesquisa, ora apresentada, abordou a história da escola entre sua fundação em 1971 até o ano de 2010.

O estudo de caso de perspectiva longitudinal foi construído em retrospectiva a partir de fatos, situações e eventos relembrados e relatados em entrevistas semi-estruturadas. Em relação à definição da quantidade de entrevistas, foram consideradas as recomendações de que para a análise dos processos institucionais em escolas devem-se abordar diferentes camadas do sistema escolar (Casassus, 2002). Assim, foram entrevistados 28 indivíduos, dentre eles professoras, diretoras, ex-diretoras, coordenadoras pedagógicas, funcionários administrativos, técnicos da Secretaria Municipal de Educação e pais de alunos. As entrevistas foram feitas a partir de um roteiro previamente elaborado e por conversas informais, os quais versaram sobre a caracterização da escola, os eventos mais marcantes de sua história, os principais aspectos do cotidiano escolar, a importância conferida aos professores e à direção ao longo da história da escola, e de como se desenvolveram as relações com os diversos públicos da comunidade escolar.

Também foi realizada a coleta de dados por observação direta e pesquisa documental. No tocante à observação direta, um dos pesquisadores visitou a escola dez vezes em diferentes dias e horários, dentre eles, nos horários e intervalos de aula e turno (manhã e tarde). O pesquisador permaneceu no estabelecimento por 60 minutos, a cada visita, e observou o cotidiano entre professores, alunos, direção e funcionários. A sala da direção, dos professores, o pátio e a cantina foram os espaços privilegiados da observação direta. Nessa observação, buscou-se identificar atitudes dos professores em relação aos alunos e da diretora em relação aos professores e funcionários da escola e vice-versa. A observação direta foi registrada e incorporada às laudas de transcrição das entrevistas semi-estruturadas, totalizando duzentas laudas. Na pesquisa documental deu-se ênfase às atas de reuniões do colegiado e das Assembleias Escolares bem como dos documentos da Secretaria Municipal da Educação compreendendo o período de 1994 a 2010. Considerou-se importante consultar tais documentos porque são os que contêm as deliberações e diretrizes formalizadas referentes à gestão educacional. Cabe salientar que o recorte de tempo utilizado para a pesquisa documental se deu em função do acesso e da disponibilização dos documentos. 
CONTRIBUIÇÕES DA TEORIA INSTITUCIONAL PARA A ANÁLISE DA GESTÃO DE ESCOLAS: UM ESTUDO DE CASO DE ESCOLA PÚBLICA BRASILEIRA BEM SUCEDIDA NOS ÍNDICES DE DESEMPENHO DA EDUCAÇÃO BÁSICA

\subsection{Tratamento e análise dos dados}

Finalizada a coleta de dados, iniciou-se o tratamento e a análise dos dados. O tratamento seguiu a estratégia da construção de narrativas (Langley, 1999). Nessa estratégia buscou-se a cronologia dos eventos mediante a ordenação detalhada dos fatos e situações relatadas, conjugando-os com a observação direta e os dados da pesquisa documental. A construção da narrativa refere-se a um texto que exibe as representações dos entrevistados, concatenados aos fatos descritos, observados e documentados (George; Bennet, 2005). No tratamento dos dados os seguintes procedimentos foram seguidos. Primeiro, a escola foi caracterizada. Segundo, periodizaram-se as recordações sobre a história da escola. Terceiro, definiu-se o recorte temporal. Tal recorte foi composto por períodos que variaram em função dos fatos relatados. Esses fatos corresponderam aos marcos políticos da sociedade brasileira e foi organizado em três períodos. O primeiro período correspondeu aos anos de 1971 a 1978, caracterizando o período do regime autoritário. O segundo período englobou os anos de 1979 a 1993 caracterizados pela redemocratização da sociedade brasileira. E por fim o terceiro período, denominado de consolidação da democracia diz respeito ao período de 1994 a 2010. Assim, recuperou-se a história da organização ao mesmo tempo em que se contextualizou o ambiente institucional.

Após o tratamento dos dados, iniciou-se a análise. A lógica da análise fundamentou-se, em primeiro momento, na estratégia dedutiva, em que se caminha da teoria para os dados. Em um segundo momento, valeu-se da análise baseada na lógica indutiva, determinando as categorias de pesquisa vis-à-vis os dados (Miles; Huberman, 1994). A lógica de análise seguiu os seguintes passos. De acordo com o referencial teórico, estipulou-se três categorias de pesquisa que correspondiam ao ambiente institucional, valores e gestão educacional constantes na figura 1 do referencial teórico. Essas categorias estão descritas no quadro 1.

REAd | Porto Alegre - Edição 83 - N 1 - Janeiro/Abril 2016 - p. 193-224 
Ângela França Versiani, Sérgio Fernando Loureiro Rezende \& Antônio Carlos Pereira

\begin{tabular}{|l|l|}
\multicolumn{2}{|c|}{ Quadro1 - Categorias dedutivas de pesquisa } \\
\hline \multicolumn{1}{|l|}{ Categorias de pesquisa identificadas dedutivas } \\
\hline Ambiente Institucional & $\begin{array}{l}\text { Regras ditadas pelas regulamentações } \\
\text { governamentais sobre educação e pressões das } \\
\text { associações de classe na área educacional }\end{array}$ \\
\hline Valores & $\begin{array}{l}\text { Significados atribuídos as práticas e interações } \\
\text { que elaboram a gestão educacional }\end{array}$ \\
\hline Gestão Educacional & $\begin{array}{l}\text { Articulação dos recursos e das condições } \\
\text { materiais e humanas presentes no processo } \\
\text { educativo mediante práticas administrativas e } \\
\text { pedagógicas. }\end{array}$ \\
\hline
\end{tabular}

Fonte: Elaborado pelos autores do artigo

Inicialmente, as entrevistas foram analisadas de acordo com essas três categorias, a partir da identificação das falas dos entrevistados referindo-se a elas.

Para prosseguir na análise, foram consideradas as sugestões de Barley e Tolbert (1997) e as recomendações de Zilber (2008) no que tange aos processos de institucionalização. De acordo com esses autores, em vez de representar a institucionalização como governada por leis universais, deve-se identificar os episódios de interação e os significados atribuídos pelos indivíduos a esses episódios. A partir daí identificaram-se, nas entrevistas, os conteúdos de falas relevantes e recorrentes sobre os acontecimentos da escola, envolvendo a gestão educacional. Essa análise foi de caráter indutivo. Buscaram-se nas falas dos entrevistados, as descrições, explicações, justificativas, crenças em relação à gestão da escola e seu contexto. Nessa análise emergiu a existência de três categorias indutivas de pesquisa, a saber: estilo de gestão das diretoras, papel do professor e relacionamentos na escola. Essas categorias estão descritas no quadro 2 e referem-se às práticas administrativas e pedagógicas efetivadas na escola que apareceram nos depoimentos e materializaram a gestão educacional. Desse modo, a categoria dedutiva gestão educacional correspondeu a três categorias indutivas observadas nos depoimentos.

Quadro 2 - Categorias indutivas de pesquisa

Categorias de pesquisa identificadas indutivamente

\begin{tabular}{|l|l|}
\hline $\begin{array}{l}\text { Estilo de gestão das } \\
\text { diretoras }\end{array}$ & $\begin{array}{l}\text { Atitudes da direção da escola em relação à } \\
\text { articulação dos recursos materiais e humanos }\end{array}$ \\
\hline Papel do professor & $\begin{array}{l}\text { Obrigações com caráter de exigência em relação } \\
\text { à posição do profissional docente }\end{array}$ \\
\hline Relacionamentos na escola & $\begin{array}{l}\text { Tipo de convivência da comunidade escolar no } \\
\text { âmbito da escola }\end{array}$ \\
\hline
\end{tabular}

Fonte: Elaborado pelos autores do artigo

REAd | Porto Alegre - Edição 83 - N 1 - Janeiro/Abril 2016 - p. 193-224 
CONTRIBUIÇÕES DA TEORIA INSTITUCIONAL PARA A ANÁLISE DA GESTÃO DE ESCOLAS: UM ESTUDO DE CASO DE ESCOLA PÚBLICA BRASILEIRA BEM SUCEDIDA NOS ÍNDICES DE DESEMPENHO DA EDUCAÇÃO BÁSICA

Para analisar se ocorreu a institucionalização da gestão educacional, observou-se recorrências das cinco categorias de pesquisa, a partir do ponto de vista dos entrevistados tendo em vista o período de 1971 a 2010 (Vide quadro 3). Na primeira categoria, ou seja, "ambiente institucional" verificou-se o quanto se dizia que a escola atendia às pressões do ambiente institucional (grau de conformidade ao ambiente). Na segunda categoria, "Valores", foram observadas as recorrências dos significados das falas em relação aos alunos, professores e relacionamentos na escola. A terceira categoria "Estilo de gestão da diretora“" referiu-se ao quanto se dizia delegar a administração da escola. Já a quinta categoria, "Papel do professor" implicou as repetições relatadas ao comportamento do professor em relação ao ensino. E a quinta categoria, "Relacionamentos na escola," as repetições mencionadas sobre a qualidade dos relacionamentos na comunidade escolar.

$\mathrm{Na}$ análise de como os processos ocorreram, procurou-se buscar associações representadas que revelassem as maneiras pelas quais os valores foram veiculados, introjetados e ganharam persistência. Foram identificados três grupos de relações envolvendo os valores. O grupo 1 refere-se à associação entre ambiente institucional e valores. Nesse grupo mostram-se os valores ou normas veiculados pelo ambiente institucional e a aceitação ou rejeição, tendo por referência as práticas administrativas ou pedagógicas exercidas na escola. O grupo 2 diz respeito aos valores e papel do professor. Essa associação mostra como a gestão educacional transmite valores e as maneiras pelas quais os agentes envolvidos lidam com esses valores pela definição de suas obrigações em relação às práticas pedagógicas ou administrativas. Por fim, o grupo 3 inclui as associações entre estilo de gestão, valores e relacionamentos na escola. Esse grupo mostra como as atitudes da direção criam e reforçam valores, gerando efeitos nos relacionamentos da escola.

A partir dessa análise concluiu-se que houve a institucionalização de um modelo de gestão educacional. Essa conclusão é apresentada nas próximas seções que tratam da apresentação empírica dos dados e de sua discussão teórica. 
Ângela França Versiani, Sérgio Fernando Loureiro Rezende \& Antônio Carlos Pereira

\section{APRESENTAÇÃO DOS DADOS}

\subsection{Caracterização da Escola Municipal João Pinheiro}

A EMJP localiza-se no Bairro Alto dos Pinheiros, Região Noroeste de Belo Horizonte, cujas famílias dos seus alunos percebem vencimentos de 2,6 salários mínimos, sendo consideradas como "famílias pobres" pelos entrevistados. Os alunos da escola totalizam 800 crianças, dos três aos doze anos de idade, distribuídas entre a educação infantil e o segundo ciclo do Ensino Fundamental. Tais crianças são atendidas por 55 professoras, das quais $70 \%$ estão na rede municipal desde 1995 e 100\% possui escolaridade de nível superior. Da fundação até o ano de 2010, a escola foi dirigida por cinco diretoras, sendo que a primeira delas esteve 20 anos à frente da escola.

\subsection{A Gestão educacional no período de 1971-78 : os anos de ditadura e repressão}

Ambiente institucional e valores: Em 1971, quando o Brasil vivia o endurecimento da ditadura militar e acelerava seu processo de urbanização, a escola EMPJ foi criada. Naquela época, não havia obrigatoriedade de financiamento da educação pelos estados e pela União, e foi transferida aos munícipios a responsabilidade de fazer frente à demanda por escolarização. As normas que regiam as escolas eram promulgadas e centralizadas pelas Delegacias Regionais de Ensino pertencentes à estrutura da Secretaria de Estado de Educação. Essas normas rezavam, por exemplo, que o objetivo do currículo no ensino de $1^{\circ}$. Grau era as sondagens de aptidões e iniciação para o trabalho (LDB,5692/71). As escolas deveriam garantir índices de proficiência dos alunos nessas aptidões, suprindo-lhes carências e deficiências a partir do ensinamento de conteúdos formais que lhes permitiriam progressões escolares (Rocha, 2009). O regimento interno (RI) das escolas reproduziam as diretrizes pedagógicas promulgadas pelas Delegacias Regionais de Ensino. Entretanto, os protagonistas mais antigos, que viveram os primeiros anos da escola, informam em seus relatos que não tinham o RI como referência no que diz respeito às questões pedagógicas relativas à aprovação do aluno. Segundo os entrevistados,

“[...] já naquele tempo, havia a preocupação em garantir que as crianças acompanhassem seus colegas de mesma idade".

REAd | Porto Alegre - Edição 83 - N 1 - Janeiro/Abril 2016 - p. 193-224 
CONTRIBUIÇÕES DA TEORIA INSTITUCIONAL PARA A ANÁLISE DA GESTÃO DE ESCOLAS: UM ESTUDO DE CASO DE ESCOLA PÚBLICA BRASILEIRA BEM SUCEDIDA NOS ÍNDICES DE DESEMPENHO DA EDUCAÇÃO BÁSICA

A preocupação com a adaptação da criança significava uma margem que permitia avanços para a próxima série, sem que os alunos atingissem os índices de proficiência estabelecidos pelas normas institucionais. Cabe destacar que essa prática contrariava o RI. E de que após, 15 anos, em 1994, tal prática seria incorporada às diretrizes do governo municipal embasadas na filosofia da chamada Escola Plural.

Lembrando o período da ditadura militar, indagou-se aos entrevistados sobre as reações das Inspetoras de Ensino perante as práticas pedagógicas não ortodoxas das aprovações. Os entrevistados ressaltam a burocracia no comportamento de tais inspetoras:

“[...] as inspetoras de ensino não se preocupavam com isso (aprovação dos alunos). Desde que os diários de classe e os documentos burocráticos estivessem corretamente preenchidos, tudo bem".

Valores e papel do professor: Ainda referindo-se ao período entre 1971-78, perguntou-se aos professores sobre as causas do fracasso escolar. Os entrevistados enfatizaram que o fracasso escolar era um problema individual do aluno e de que os docentes eram compromissados com o ensino, tanto quanto nutriam sentimentos de confiança em relação ao aluno. De acordo com as entrevistas:

[...] "O fracasso escolar é um problema de inadequação do aluno, a uma escola, que privilegiava, sobretudo, o conteúdo de ensino. O papel do professor era ensinar e reprovar aqueles com baixo desempenho".

[...] "Naquele tempo, os professores confiavam em seus alunos, acreditavam que eles iriam para a faculdade".

Estilo de gestão, valores e relacionamentos na escola: Embora, entre 1971 e 1978, a sociedade brasileira fosse cerceada em sua participação política, a direção da escola praticava uma gestão administrativa com delegação de decisão, o que lhe conferia respeito, admiração e confiança pelo estilo participativo. A diretora no ponto de vista dos entrevistados:

[...] "(a diretora) reforçava o compartilhamento de decisões e a delegação à equipe pedagógica", sendo uma figura que marcou a escola, que fez da João Pinheiro o que a João Pinheiro é hoje. Uma escola de respeito".

Ao mesmo tempo em que representava o poder hierarquizado e, naquele tempo, autoritário, a diretora também carregava o seu contrário, incentivava a autonomia do profissional. Os entrevistados são assertivos nos relatos quanto à autonomia docente.

REAd | Porto Alegre - Edição 83 - N 1 - Janeiro/Abril 2016 - p. 193-224 
“[...] eu tinha autonomia. Então eu podia criar os projetos, fazer as reuniões. Porque ela [a diretora] delegava isso para a gente. Então a gente já trabalhava dessa forma e as coisas fluíam mesmo naquele período autoritário."

Considera-se que o estilo participativo de gestão da diretora e sua capacidade de organização contribuíram para os relacionamentos bons na escola. Também ressalta-se a confiança entre os pares na promoção da qualidade desse relacionamento. De acordo com os entrevistados:

[...]“O ambiente de trabalho era muito bom, por causa da diretora, a escola era organizada. Uma escola sempre bem cuidada. Por causa da confiança entre as professoras. Todo mundo muito afinado“.

\subsection{A Gestão educacional no período de 1979-1993: a democratização do acesso a educação}

Ambiente institucional e valores: No final dos anos 70 e durante os idos de 80, houve a expansão do ensino fundamental. A democratização do acesso à educação, neste período, ocorreu sob a égide do centralismo e da verticalização do sistema. Isto é, houve a multiplicação de instâncias intermediárias do estado para o controle da educação, o que aumentou a burocratização e consumiu recursos que deveriam ser dedicados a sua atividade fim (Libâneo;Oliveira;Toschi, 2003). A obsessão pelo controle replicava instâncias que reproduziam, nos estados e municípios, as mesmas atividades da esfera federal. De currículos escolares a materiais didáticos, tudo era decidido em nível central, em uma tentativa de não permitir aos municípios e às escolas qualquer poder de decisão sobre o seu fazer cotidiano. A municipalização do ensino ocorrida no regime militar, apenas transferiu obrigações para os municípios, sem lhes dar os meios técnicos e financeiros e sem reconhecê-los como instância administrativa. Além disso, o planejamento de ações capazes de enfrentar o crescimento do sistema educacional ficava comprometido pela ausência de instrumentos de avaliação do sistema educacional (Mello,1991).

Em 1979, em meio à retomada das lutas trabalhistas no país, acontece a primeira grande paralisação do magistério da rede estadual de ensino de Minas Gerais. O leque de pleitos por mais democracia surgia nas palavras de ordem "diretas para diretor". Ainda que, na primeira 
CONTRIBUIÇÕES DA TEORIA INSTITUCIONAL PARA A ANÁLISE DA GESTÃO DE ESCOLAS: UM ESTUDO DE CASO DE ESCOLA PÚBLICA BRASILEIRA BEM SUCEDIDA NOS ÍNDICES DE DESEMPENHO DA EDUCAÇÃO BÁSICA

greve, em 1979, não houvesse uma pauta para a rede municipal, na EMJP, segundo os entrevistados havia liberdade de discussão. Conforme as entrevistas:

"[...] havia muito espaço para discutir o movimento grevista, com tranquilidade, naquela época."

O final dos anos 70 e inicio dos 80 representam o momento da incorporação das influências do sindicato da categoria na vida escolar, pressionando a democratização das relações no interior da escola e desta com a comunidade de seu entorno Os entrevistados relembram tal influência e reconhecem os conflitos e disputas dentro da rede de ensino e na escola :

“[...] o sindicato, fundado em 1980, unificou as demandas por mais participação tanto dos professores quanto da comunidade na definição dos rumos da escola. E nós seguíamos a onda. Foi um processo árduo, difícil em que os conflitos começaram a aparecer”.

Valores e papel do professor : Em 1989 foi eleita a primeira diretora. Cabe destacar que essa diretora ocupou o cargo desde a fundação da escola, e foi reeleita para um segundo mandato, mantendo o estilo participativo de gestão. Todas as quatro outras gestoras foram também reeleitas. Consolida-se a noção de participação como elemento constitutivo das práticas administrativas da escola, e ao mesmo tempo reforça-se a identificação do professor com seu papel, destacando sua responsabilidade e dever junto à comunidade escolar. De acordo com os entrevistados:

“[...]Nós sempre defendíamos greve, mas com reposição"! E a gente repunha tudo e a comunidade ficava tranqüila. "Era nosso dever de professor".

Estilo de gestão, valores e relacionamentos na escola: Os espaços de participação e decisão foram ampliados dentro de uma perspectiva em que a escola e os professores assumiam a qualidade como premissa de suas ações. De acordo com as entrevistas:

"[...] a escola assumiu a qualidade como uma questão institucional e como processo coletivo, criando um clima que alterava positivamente o resultado da ação pedagógica”.

Além das reivindicações por melhorias salariais e das condições de trabalho, havia também aquelas que apontavam para a necessidade de se construir uma nova ordenação da 
Ângela França Versiani, Sérgio Fernando Loureiro Rezende \& Antônio Carlos Pereira

escola capaz de assegurar a inclusão de todos. Os depoimentos são claros quanto aos ganhos da participação.

"[...] as eleições diretas com a participação da comunidade foi um ganho da sociedade como um todo, tanto para os professores como para a própria comunidade. É a sociedade na construção da sociedade, da cidadania, Belo Horizonte, Minas, Brasil”.

\subsection{A Gestão educacional no período de 1994- 2010: a Escola Plural}

Ambiente institucional e valores: Em 1994, a Prefeitura de Belo Horizonte iniciou o processo de implantação da Escola Plural. A Escola Plural condensava as diretrizes da política municipal de Belo Horizonte, cuja proposta era reduzir a evasão, repetência e exclusão do aluno pela ampliação do seu tempo de permanência na escola, eliminação da estrutura seriada e nova organização dos tempos pedagógicos dos profissionais (Mazzilli, 2000). Em 1995, a Escola plural foi implantada nos estabelecimentos de primeira a quarta série do ensino fundamental. A construção coletiva, envolvendo educadores, alunos e seus pais, foi uma de suas marcas (Escola Plural, 2003). De acordo com os entrevistados, tal filosofia já era adotada pela EMJP.

“[...] Muito do que se propunha pela Escola Plural já vinha sendo realizado na EMJP: o trabalho coletivo e a flexibilidade no trato da seriação. A Escola Plural não foi surpresa para nós. Nós já praticávamos muito do que ela propunha".

Se, por um lado, a EMPJ antecipadamente adotou alguns preceitos da escola plural, por outro, não se deve desconsiderar as resistências enfrentadas em relação a essa proposta. De acordo com as entrevistas:

“[...] a Escola Plural 'baratinou' uma série de professores, um grande número que resistiu e que não viu seu rosto nesse projeto. Como não havia mais reprovação, nós tínhamos que garantir que os alunos aprendessem de fato. Em alguns casos, mantivemos as reprovações. Nós bancamos”.

Após 15 anos da implantação da escola plural, os entrevistados acreditam que a "escola plural está acabando", devido a medidas adotadas pela Secretaria Municipal de Educação, como, por exemplo, a volta do Boletim Escolar e a exigência de maior rigor no cumprimento dos currículos. A partir de 2000, a Secretaria Municipal de Educação de Belo Horizonte (MG) começou a valer-se dos indicadores externos para avaliar a qualidade da educação no

REAd | Porto Alegre - Edição 83 - N 1 - Janeiro/Abril 2016 - p. 193-224 
CONTRIBUIÇÕES DA TEORIA INSTITUCIONAL PARA A ANÁLISE DA GESTÃO DE ESCOLAS: UM ESTUDO DE CASO DE ESCOLA PÚBLICA BRASILEIRA BEM SUCEDIDA NOS ÍNDICES DE DESEMPENHO DA EDUCAÇÃO BÁSICA

município. Segundo, os documentos oficiais dessa Secretaria os conceitos centrais da Escola Plural, como universalização do acesso, inclusão, ou o respeito às diferenças estão mantidos. Mesmo porque não poderia ser diferente, já que esses pressupostos estão hoje consagrados na LDB (Lei 9394), assim como a participação da comunidade escolar nos órgãos diretivos, ou a autonomia pedagógica do professor. A diretriz educacional promulgada implica retomar a ideia de uma "rede" de ensino como um sistema educacional pautado em metas e maior grau de padronização curricular e de organização.

Entretanto, a valorização dos indicadores externos de avaliação preconizados pela Secretaria Municipal de Educação de Belo Horizonte não aparece nos relatos das entrevistas, O índice de desempenho da educação básica não norteia as ações pedagógicas e é visto com crítica e cautela. Os entrevistados apresentam ceticismo quanto a tal indicador.

“[...] O IDEB é uma preocupação superficial com estatística, são só números. Isso não faz diferença. Esses indicadores, essas avaliações sistêmicas, se elas garantissem a qualidade, o Brasil estaria em primeiro lugar no PISA" (Programa Internacional de Avaliação de Aluno)".

Valores e papel do professor: A proposta de avaliação da escola plural exigia um grande envolvimento da comunidade escolar, e a direção da escola procurou promover ainda mais o envolvimento da comunidade escolar, em especial do professor com as atividades de ensino. Segundo os entrevistados:

“[...] a diretora sempre buscou esse envolvimento, de uma maneira muito organizada, como parte do processo de ensino. Esse envolvimento significou por parte do professor uma necessidade de maior comprometimento com os alunos.

“[...] Com o fim da reprovação, aumentou ainda mais a nossa responsabilidade sobre o aprendizado dos alunos. Como não havia mais reprovação, nós tínhamos que garantir que eles aprendessem para valer."

É necessário destacar que o trabalho docente não se pautava e ainda não se pauta por um projeto pedagógico global da escola. Constatou-se que não existe a formalização de um projeto coletivo da escola. Além do compromisso com os alunos, o que está incorporado ao cotidiano da escola são projetos educacionais fragmentados e exigências administrativas pautadas em metas e prazos. As exigências de detalhamentos, prazos, bem como a rigidez das prestações de contas sobrepujam o projeto pedagógico. Conforme os depoimentos relatam:

REAd | Porto Alegre - Edição 83 - N 1 - Janeiro/Abril 2016 - p. 193-224 
“[...] Não há processos sistematizados de gestão, com exceção da prestação de contas". 95\% do tempo é gasto com a parte administrativa." Assim, os resultados obtidos pelos alunos no IDEB são até louváveis, porque o tempo aqui de encontro entre professor, coordenador e direção realmente não existe.

Estilo de gestão, valores e relacionamentos na escola: A inclusão e participação trazidas pela Escola Plural permitiu avançar um estilo de gestão que valorizasse ainda mais a relação com a comunidade, instituindo diferentes formas de interação. Os entrevistados ressaltam a ampliação do espaço educacional para a comunidade mediante atividades culturais e busca de engajamento da família nas atividades da escola. Também ressaltam a disponibilidade da escola em atender as demandas da comunidade e a melhoria das condições de ensino. A orientação de gestão das diretoras é vista como contribuindo positivamente para o atendimento a tais demandas.

"[...] Atividades ligadas a música, artesanato, ou esportes são realizadas nos espaços da escola durante alguns fins de semana. E de quinze em quinze dias vai uma atividade para ser feita com o pai e a mãe".

"[...] nós possuímos disponibilidade para atendimento às demandas da comunidade escolar e preocupamos com a melhoria das condições de ensino".

"[...] Cada direção que por aqui passou buscou elevar o nível da escola. Eu acho que isso vai durar para sempre".

Quanto às relações internas entre professores - professores, ou entre professoresdireção-coordenação, a opinião é a de que, o fator tempo e tradição contribuíram para o desenvolvimento de relações sociais amistosas e cordiais entre a comunidade escolar.

"[...] O clima é bom, as pessoas se entendem, tem pouca gente novata aqui. O fato de os pais dos alunos de hoje terem sido eles também alunos da escola reforça essa característica".

\section{ANÁLISE DOS DADOS}

Os dados demonstram a consolidação de um padrão de gestão educacional desenvolvido ao longo do período de 1971-2010. Essa conclusão se baseia em cinco recorrências observadas. A primeira recorrência refere-se à baixa conformidade da gestão da escola às pressões coercitivas do ambiente. A segunda diz respeito ao estilo de gestão das diretoras, REAd | Porto Alegre - Edição 83 - N 1 - Janeiro/Abril 2016 - p. 193-224 
CONTRIBUIÇÕES DA TEORIA INSTITUCIONAL PARA A ANÁLISE DA GESTÃO DE ESCOLAS: UM ESTUDO DE CASO DE ESCOLA PÚBLICA BRASILEIRA BEM SUCEDIDA NOS ÍNDICES DE DESEMPENHO DA EDUCAÇÃO BÁSICA

caracterizado pela delegação de autoridade aos professores. A terceira recorrência diz respeito ao papel do professor identificado com o ensino. A quarta é caracterizada pela qualidade amistosa das relações sociais desenvolvidas na comunidade escolar. E, por fim, os valores que destacaram a importância conferida ao aluno, o dever do professor com o ensino, a confiança entre os membros da comunidade escolar e o diálogo nos relacionamentos. Tais valores apresentaram como as ligações que permitiram acoplar os diferentes elementos da escola, tais como direção, professores, alunos e pais. Tais ligações foram possíveis porque o corpo docente assumiu o papel de protagonista do ensino, agindo em função do aluno. Desse modo, a institucionalização do modelo de gestão educacional relacionou períodos alternados de baixa conformidade às pressões coercitivas do ambiente com a sedimentação dos valores de confiança e diálogo nos relacionamentos, importância conferida ao aluno e o senso de dever do professor com o ensino. O quadro 3 representa as dimensões da institucionalização da gestão educacional e sua recorrência no tempo.

Quadro 3 - Dimensões da institucionalização e sua recorrência temporal

\begin{tabular}{|c|c|c|c|c|}
\hline \multicolumn{2}{|c|}{ Institucionalização da gestão educacional } & \multicolumn{3}{|c|}{ Recorrência no tempo } \\
\hline Dimensões & Caracterização & 1971-1978 & 1979-1993 & 1994-2010 \\
\hline Ambiente Institucional & $\begin{array}{l}\text { Grau de conformidade } \\
\text { da escola ao ambiente }\end{array}$ & $\begin{array}{c}\text { baixa } \\
\text { conformidade }\end{array}$ & $\begin{array}{c}\text { alta } \\
\text { conformidade }\end{array}$ & $\begin{array}{c}\text { baixa } \\
\text { conformidade }\end{array}$ \\
\hline Estilo de gestão & Delegação & presença & presença & presença \\
\hline Valores & $\begin{array}{c}\text { Importância conferida } \\
\text { ao aluno } \\
\text { Confiança } \\
\text { Senso de dever do } \\
\text { professor } \\
\text { Diálogo }\end{array}$ & presença & presença & presença \\
\hline Papel do professor & $\begin{array}{c}\text { Ênfase } \\
\text { no ensino }\end{array}$ & presença & presença & presença \\
\hline $\begin{array}{c}\text { Relacionamentos na } \\
\text { escola }\end{array}$ & Amistosas & presença & presença & presença \\
\hline
\end{tabular}

Fonte: Dados da pesquisa

\subsection{Detalhamento da análise e discussão dos resultados}

Durante o período analisado (1971-2010), houve alternâncias da conformidade da EMPJ em relação às pressões coercitivas do ambiente, destacando a recorrência da baixa conformidade. Essa constatação se manifesta no primeiro período (1971-78) e no terceiro 
Ângela França Versiani, Sérgio Fernando Loureiro Rezende \& Antônio Carlos Pereira

período (1994-2010). No primeiro período, o acoplamento entre as normas pedagógicas da Secretaria Municipal de Educação e o fazer pedagógico da escola, no que diz respeito às prescrições estabelecidas no Regimento Interno dá mostras de interdependências fracas, uma vez que não era adotado como a principal referência na aprovação do aluno. Esse mesmo tipo de acoplamento é observado quando da introdução das práticas preconizadas pela Escola Plural e daquelas que valorizam os indicadores de avaliação externas, como por exemplo, o IDEB.

A constatação de que as práticas pedagógicas desenvolvidas na EMPJ mostram interdependências fracas com as pressões legais, demonstra a ideia de que as organizações educacionais não são destinatárias passivas das pressões dos seus ambientes, mas podem ser espaços de oposição aos valores emanados do ambiente porque desenvolvem agência (Thornton; Ocasio, 2008). No presente caso, a agência se manifestou mediante as práticas pedagógicas desenvolvidas pelos professores em relação às aprovações e reprovações dos alunos, que muitas vezes, contrariaram as normas do ambiente institucional. Tal constatação reforça o argumento teórico de que há uma condição fenomenológica dos arranjos estruturais que são objetos dos processos de institucionalização (Tolbert; Zucker, 1999). Essa condição aparece no caso pesquisado, sobretudo, na importância que o "aluno" adquire enquanto elemento que justifica o descompasso entre o prescrito pelas pressões coercitivas do ambiente e daquilo que é realizado no âmbito da escola. É pelo aluno e para o aluno que se justificam o desacoplamento entre o promulgado pelas normas do ambiente institucional e o efetivamente adotado pelas práticas pedagógicas. Essa constatação confirma os argumentos de Zilber (2008) de que os valores possuem materialidade própria diferindo das práticas per-se, embora ambos estejam entrelaçados.

A importância conferida ao aluno foi ao longo de todo o período analisado (1971-2010) veiculado pelo discurso da confiança. Seja da confiança da direção atribuída aos professores pelas diretoras, seja daquela que os professores nutriram em relação às capacidades dos alunos, seja na crença dos atributos que definem o papel do professor como ator responsável pela aprendizagem. As obrigações e normas com caráter de exigências imputadas ao professor permaneceram inalteradas nos três períodos analisados. Ao professor é exigida a flexibilidade para atender as demandas do aluno, desde que se garanta o aprendizado mediante a transmissão de conteúdos.

A responsabilidade do professor com o aluno destacou-se como um valor que parece ter conferido legitimidade à escola mediante a elaboração de uma identidade positiva. Assim os

REAd | Porto Alegre - Edição 83 - N 1 - Janeiro/Abril 2016 - p. 193-224 
CONTRIBUIÇÕES DA TEORIA INSTITUCIONAL PARA A ANÁLISE DA GESTÃO DE ESCOLAS: UM ESTUDO DE CASO DE ESCOLA PÚBLICA BRASILEIRA BEM SUCEDIDA NOS ÍNDICES DE DESEMPENHO DA EDUCAÇÃO BÁSICA

dados demonstram uma escola que veicula uma lógica institucional de "exaltação do aluno". A lógica institucional refere-se ao conteúdo do significado envolvido nas práticas sustentadas e reproduzidas pelos agentes da organização (Thornton; Ocasio, 2010). A lógica institucional de "exaltação do aluno" deu mostras de estar relacionada à elaboração de um discurso de confiança no tocante à importância do papel do professor na aprendizagem escolar. Estudos empíricos sobre os aspectos ideacionais da institucionalização mostram que discursos ou teorizações constituem mecanismos centrais no processo de difusão de valores (Phillips et al., 2004).

Nesse ponto da discussão, é possível a conjectura de que, a lógica de "exaltação do aluno" esteja sendo difundida no sistema educacional. Isto porque a referida escola possui desempenho favorável nas avaliações da educação básica, o que lhe confere a posição de ator relevante no sistema educacional. Segundo a teoria institucional, organizações que são bem sucedidas em lidar com problemas oriundos de causas ambíguas disseminam atributos específicos no campo a que pertencem. Nas palavras de Dimaggio e Powell (1991, p.79) "as organizações tendem a tomar como modelo em seu campo outras organizações que elas percebem ser mais legítimas ou bem-sucedidas". A legitimidade implica codificar valores em um determinado domínio da vida institucional mediante a apropriação de determinados discursos (Zilber, 2008).

No caso relatado, o discurso da confiança aparece não só em relação ao professor e aluno, mas também na qualificação das relações desenvolvidas entre a direção e o corpo docente. No presente caso, a confiança nessas relações parece ter sido fomentada principalmente em função do estilo de gerenciamento que, já, em seus primórdios, em tempos de ditadura e repressão, contraditoriamente, guiou-se pela busca de participação do corpo docente nas questões administrativas e pedagógicas. Tal participação se viu fortalecida com a democratização da sociedade brasileira e com as eleições para diretor, reforçando ainda mais a proximidade entre os pares.

Assim tem-se que a "confiança nos relacionamentos" mediante práticas que a fortalecem via participação do corpo docente nas questões administrativas e pedagógicas apresentaram-se como os valores que perpassam a gestão educacional, constituindo os significados que denotam os aspectos ideacionais e simbólicos (Zilber, 2008) desta escola que possui bom desempenho escolar. Frente a tal constatação é plausível a suposição de que os valores de confiança atribuídos pela direção da escola aos professores permitiu desencadear e reforçar o desenvolvimento de práticas participativas de gestão educacional. Tais práticas

REAd | Porto Alegre - Edição 83 - N 1 - Janeiro/Abril 2016 - p. 193-224 
Ângela França Versiani, Sérgio Fernando Loureiro Rezende \& Antônio Carlos Pereira

representam as prescrições duradouras (Giddens, 2003) da gestão educacional, desencadeadas pelas ações das quatro diretoras da escola.

As quatro gestões garantiram apoio, bem como o espaço de autonomia e liberdade ao exercício profissional do docente. Observa-se que ao longo do tempo, desenvolveu-se um estilo de gerenciamento que buscou o diálogo entre os diversos públicos que compõem a comunidade escolar, contribuindo para relações sociais amistosas e cordiais. Essa constatação mostra claramente como agentes (diretoras) criaram condições para a escola construir legitimidade. Tal resultado vai de encontro às alegações dos clássicos da teoria institucional, tais como Selznick (1957) e de autores mais contemporâneos, por exemplo, Kraatz e Moore (2002) de que a liderança possui um papel ativo na institucionalização, criando e preservando valores. Cabe ressaltar que as quatro gestões representaram o mesmo estilo participativo de gestão em resposta às pressões externas e internas ao longo de todo o período analisado. Esse tipo de resposta caracteriza o que é denominado de modo proativo de institucionalização (Fleck, 2007), em que o aprendizado organizacional é a chave do sucesso de longo prazo da organização.

O modo proativo de institucionalização esteve atrelado aos valores de confiança e as relações amistosas fomentadas pelas direções da escola. Essa evidencia reforça as colocações de Casassus (2002), quando afirma que o ambiente emocional da escola, principalmente as relações entre os professores e seus alunos, e aquelas entre os próprios professores, e destes com a direção e a comunidade são mais significativos que outras características tais como materiais didáticos ou formação de professores. Como consequência dessas alegações, observaram-se relações entre os valores de diálogo e as relações amistosas estabelecidas na comunidade. Essas relações parecem constituir os recursos simbólicos que oferecem aos agentes da escola (professores, diretores e comunidade escolar) possibilidade de reinterpretar suas práticas e ações.

É importante sublinhar a homogeneidade nas características da formação docente e da visão sobre o gerenciamento da escola. As quatro gerações de diretoras adotaram como objetivo de gestão o valor da melhoria das condições de aprendizagem dos alunos e a determinação de gerir a escola em torno de um ideário coletivo. Contudo, curiosamente, não se observou a tradição de se trabalhar em torno de um projeto pedagógico formal, questionando a concepção teórica dominante na educação, em que, a formalização do projeto político pedagógico é a condição necessária para dar coesão e direcionamento às ações dos professores na sala de aula (Hora, 2007; Soares, 2004). Os resultados desta pesquisa relativiza 
CONTRIBUIÇÕES DA TEORIA INSTITUCIONAL PARA A ANÁLISE DA GESTÃO DE ESCOLAS: UM ESTUDO DE CASO DE ESCOLA PÚBLICA BRASILEIRA BEM SUCEDIDA NOS ÍNDICES DE DESEMPENHO DA EDUCAÇÃO BÁSICA

a supremacia do projeto político pedagógico formal como prática pedagógica central à institucionalização da gestão educacional da referida escola, sugerindo desacoplagens entre o projeto político pedagógico formal e as atividades de trabalho dos professores.

Essa constatação contraria pontos de vista de diversos autores, tais como Soares (2004) quando afirma que o projeto pedagógico consistente favorece a criação de um clima de desafio intelectual. Esse desafio, na EMJP não foi construído em torno da racionalidade proporcionada por um projeto político pedagógico objetivamente deliberado. Embora não se desqualifique a importância de tal projeto, é lícito afirmar que as ações emergentes desenvolvidas entre professoras e direção mediante diálogos e compromisso com os alunos parecem constituir as ligações fortes que acoplam elementos distintos da escola e parecem estar relacionados aos efeitos positivos de aprendizagem dos alunos. O presente caso demonstra que embora as escolas sejam consideradas como sistemas frouxamente acoplados (Weick, 1976) os valores são capazes de reconciliar suas incompatibilidades estruturais, surtindo efeito em seu público-alvo. Desse modo, pode-se concluir que o elemento de destaque desta escola de bom desempenho escolar refere-se à institucionalização de uma gestão educacional que valoriza o aluno, destaca o professor como protagonista do ensino e desenvolve uma gestão administrativa centrada nas sugestões e críticas advindas da comunidade escolar. Tal padrão de gestão foi o que emergiu dos processos institucionais vivenciados pela EMJP ao longo dos três períodos analisados.

\section{CONSIDERAÇÕES FINAIS}

O presente trabalho teve por propósito discutir a gestão escolar à luz da perspectiva institucional. Para tanto, realizou uma pesquisa qualitativa de natureza longitudinal, abordando o período entre os anos de 1971 a 2010, junto a uma escola de bom desempenho da rede municipal de Belo Horizonte (MG). Os dados revelaram a institucionalização de um específico modelo de gestão educacional. Tal modelo conjugou a baixa conformidade da escola em relação às pressões coercitivas do ambiente, relacionamentos internos pautados na confiança e práticas participativas de gestão. No centro desse modelo prevaleceram os valores que expressam a convicção de que o mais importante é o aluno e seu aprendizado, aliada à responsabilidade dos professores com este objetivo e uma gestão que estimula a participação e autonomia do profissional docente.

REAd | Porto Alegre - Edição 83 - N 1 - Janeiro/Abril 2016 - p. 193-224 
Ângela França Versiani, Sérgio Fernando Loureiro Rezende \& Antônio Carlos Pereira

A constatação de que esses valores vinculam-se à gestão de uma escola de bom desempenho escolar levanta a suposição de que tais valores estejam sendo veiculados no conjunto das instituições públicas de ensino, representando os aspectos simbólicos que delimitam o campo organizacional das escolas públicas da educação básica. Nesse ponto, teoricamente, este trabalho vislumbra a discussão sobre a delimitação do campo organizacional das escolas, definido como uma área reconhecida da rede de organizações que veicula determinados valores.

Relembrando as colocações de DiMaggio e Powell (1993) de que um campo organizacional é determinado empiricamente e não por construtos dos pesquisadores, a principal contribuição desta pesquisa esteve em delimitar valores e significados que são veiculados por uma escola importante no sistema educacional brasileiro. O presente caso sugere que os valores de "exaltação do aluno", o "senso de dever do professor com o ensino" e a "participação da comunidade escolar" foram centrais na institucionalização da gestão educacional. Mas será que tais valores são disseminados em todo o campo organizacional das escolas públicas brasileiras? Ou delimitam lógicas institucionais particulares a esse campo?

Responder tais questões torna-se, então, o próximo passo para avançar as discussões sobre processos institucionais e gestão educacional. Essa sugestão de pesquisa visa, em outras palavras, identificar mediante métodos quantitativos, o que constitui o campo organizacional das escolas da educação básica e quais lógicas institucionais estão associadas a aprendizagem escolar. Cabe, contudo, ressaltar que, outros estudos de caso de natureza qualitativa poderiam também contribuir refinando as conclusões desta pesquisa. Aliás, o escopo da pesquisa aqui relatada, ou seja, o estudo de um único caso constitui uma limitação na generalização dos resultados que se superado por pesquisas posteriores, enriquecerá, sem dúvidas a compreensão dos fenômenos que impactam a institucionalização da gestão educacional no Brasil.

\section{REFERÊNCIAS}

ABROMAVAY, M. (Coord.) Escolas inovadoras: experiências bem-sucedidas em escolas públicas. Brasília: UNESCO, 2003.

BARLEY, S. R.; TOLBERT, P. S. Institutionalization and structuration: studying the links between action and institution. Organization Studies, v. 18, n. 1, p. 93-117, 1997.

BATTILANA, J. Agency and institutions: the enabling role of individuals' social position. Organization, v. 13, n. 5, p. 653-676, 2006.

REAd | Porto Alegre - Edição 83 - N 1 - Janeiro/Abril 2016 - p. 193-224 
CONTRIBUIÇÕES DA TEORIA INSTITUCIONAL PARA A ANÁLISE DA GESTÃO DE ESCOLAS: UM ESTUDO DE CASO DE ESCOLA PÚBLICA BRASILEIRA BEM SUCEDIDA NOS ÍNDICES DE DESEMPENHO DA EDUCAÇÃO BÁSICA

BERENDS, M. Sociology and School Choice: What We Know After Two Decades of Charter Schools. Annual Review of Sociology, v. 41, n. 1, p. 159-180, 2015

BIDWELL, Charles E. Varities of institutional theory: traditions and prospects for educational research. In: MEYER, H.D; ROWAN B (Ed.) The new institutionalism in educational: advancing research in policy: Albany: State University of New York, 2006. Cap.3, p.33-50.

BRASIL. Lei n ${ }^{\circ} 5692$, de 11 de agosto de 1971. Fixa diretrizes e bases para o ensino de $1^{\circ}$. E $2^{\circ}$. Graus. Diário Oficial União, Brasília, 12 de agosto de 1971.

BRASIL. Lei $\mathrm{n}^{\circ}$ 9.394, de 20 de dezembro de 1996. Estabelece as diretrizes e bases da educação nacional. Diário Oficial União, Brasília, 23 de dezembro de 1996.

BURCH, Patricia. Educational policy and practice from the perspective of institutional theory: crafting a wider lens. Educational Researcher, v. 36, n. 2, p. 84-95, 2007.

CAPES. Brasil. Ministério da Educação. Coordenação de Aperfeiçoamento de Pessoal de Nível Superior. Plano Nacional de Pós-Graduação - PNPG 2011-2020 / Coordenação de Pessoal de Nível Superior. - Brasília, DF: CAPES, 2010.

CASASSUS, J. Problemas e la gestión educativa en América Latina: la tensión entre los paradigmas de tipo A y el tipo B. Em Aberto, v. 19, n. 74, p. 49-69, 2002.

COHEN, M. D., MARCH, J. G.; OLSEN, J. P. A garbage can model of organizational choice. Administrative Science Quarterly, v. 17, n. 1, p. 1-25, 1972.

DACIN, M. T.; MUNIR, K.; TRACEY, P. Formal dining at Cambridge colleges: linking ritual performance and institutional maintenance. Academy of Management Journal, v. 53, n. 6, p. 1393-1418, 2010.

DIMAGGIO, Paul J.; POWELL, Walter W. The iron cage revisited: institutional isomorphism and collective rationality in organizationa field. In: DIMAGGIO, Paul J.; POWELL, Walter W. The new institutionalism in organizational analysis. Chicago: University of Chicago Press, 1991. p. 63-82.

EINSENHARDT, K. M. Building theories from case study research. Academy of Management Review, v. 14, n. 4, p. 532-550, 1989.

FAST, I. Understanding Educational Policy Formation. Sociology of Education, v. 89, n. 1, p. 59-78, 2016.

FLECK, Denise. Institutionalization and organizational long-term success. BAR-Brazilian Administration Review, v.4, n.2, p.64-80, 2007.

FONSECA, V. S. A abordagem institucional nos estudos organizacionais: bases conceituais e desenvolvimentos contemporâneos. In: VIEIRA, M. M. F.; CARVALHO, C. A. (Org.). Organizações, instituições e poder no Brasil. Rio de Janeiro: FGV, 2003. p. 47-66.

REAd | Porto Alegre - Edição 83 - N 1 - Janeiro/Abril 2016 - p. 193-224 
FUSARELLI, Lance D. Tightly coupled policy in loosely coupled systems: institutional capacity and organizational change. Journal of Educational Administration, v. 40, n. 6, p. $561-575,2002$.

GIDDENS, Anthony. A constituição da sociedade. São Paulo: Martins Fontes, 2003.

GEORGE, Alexander L.;BENNETT, Andrew. Case studies and theory development in the social sciences. Cambridge: Mit Press, 2005.331p.

GREEN, S. E.; BABB, M.; ALPASLAN, C. M. Institutional field dynamics and the competition between institutional logics: the role of rhetoric in the evolving control of the modern corporation. Management Communication Quarterly, v. 22, n. 1, p. 40-73, 2008.

GREENWOOD, R. et al. The Sage handbook of organizational institutionalism. London: Sage Publications, 2008.

GUARIDO FILHO, E. A construção da teoria institucional nos estudos organizacionais no Brasil: o período 1993-2007. 2008. Tese (Doutorado) - Universidade do Paraná, Curitiba. HATCH, M. J. Organization theory, modern symbolic and postmodern perspectives. New York: Oxford University Press, 1997.

HATCH, M. J.; ZILBER, T. Conversation at the Border Between Organizational Culture Theory and Institutional Theory. Journal of Management Inquiry, v. 21, n. 1, p. 9497,2012 .

HORA, D. L. Gestão democrática na escola. 14 ed. Campinas: Papirus, 2007.

JEPPERSON, R. L. Institutions, institutional effects and Institutionalism. In: POWELL, W. W.; DIMAGGIO, P. J. The new institutionalism in organizational analysis. Chicago: The Chicago University Press, 1991. p. 143-163.

KRAATZ, M. S.; VENTRESCA, M. J.; DENG, L. Precarious values and mundane innovations: enrollment management in American liberal arts colleges. Academy of Management Journal, v. 53, n. 6, p. 1521-1545, 2010.

LANGLEY, Ann. Strategies for theorizing from process data. The Academy Management Review, v. 24, n.4, p. 691-710,1999.

LEDESMA, M. R. K. Gestão escolar: desafios dos novos tempos. 2008. Dissertação (Mestrado) - Universidade Estadual de Campinas, Faculdade de Educação, Campinas.

LIBÂNEO, José Carlos; OLIVEIRA, João Ferreira de; TOSCHI, Mirza Seabra. Educação escolar: políticas, estrutura e organização. São Paulo: Cortez, 2003. 408p.

LOPES, F. D. Teoria institucional e gestão universitária, uma análise do processo de avaliação institucional na UNIJUI. Read, v. 5, n. 4, p. 1-21, 1999. Disponível em: <http:// read.adm.ufrgs.br/edicoes/pdf/artigo_225.pdf> 
CONTRIBUIÇÕES DA TEORIA INSTITUCIONAL PARA A ANÁLISE DA GESTÃO DE ESCOLAS: UM ESTUDO DE CASO DE ESCOLA PÚBLICA BRASILEIRA BEM SUCEDIDA NOS ÍNDICES DE DESEMPENHO DA EDUCAÇÃO BÁSICA

MARTINS, F. J. Da especificidade da gestão escolar à gestão democrática da escola: uma tomada dialética à partir dos limites atuais. Periódico do Mestrado em Educação da UCDB, n. 17, p. 63-84, 2004.

MAZZILLI, M. A. Dificuldades dos docentes na implementação de uma proposta inovadora: relato de um estudo. In: DALBEN, A. I. L. F. (Org.). Singular ou plural?: eis a escola em questão. Belo Horizonte: UFMG/FAE/GAME, 2000. p. 117-124.

MELLO, Guiomar N. Políticas Públicas de Educação. Scielo Estudos Avançados. v.15, n.13, São Paulo, dez.1991

MENEZES FILHO, N. Os determinantes do desempenho escolar do Brasil. São Paulo: Instituto Futuro Brasil, 2007. Disponível em: 〈http://www.ifb.com.br/estudos.php〉.

MEYER, H.D; ROWAN B. Instituitonal analysis and the study of education. In: MEYER, H.D; ROWAN B (Ed.) The new institutionalism in educational: advancing research in policy: Albany: State University of New York, 2006 .cap. 1, p.1-15.

MEYER, J. W.; ROWAN, B. Institucionalized organization: formal structure as a myth and ceremony. American Journal of Sociology, v. 83, n. 2, p. 340-363, 1977.

MEYER, J. W.; ROWAN, B. The structure of educational organizations. In: MEYER, J. W.; SCOTT, W. R. (Ed.). Organizational environments: ritual and rationality. Beverley Hills: Sage, 1983. p. 71-97.

MEYER, D.-H; ROWAN, B. The new institutionalism in education. Albany:State University of New York Press, 2006. 229p.

MEYER, R. E.; HÖLLERER, M. A. Does Institutional Theory Need Redirecting? Journal of Management Studies, v. 51, n. 7, p. 1221-1233, 2014.

MILES, M. B.; HUBERMAN, A. M. Qualitative data analysis: an expanded sourcebook. 2. ed. California: Sage Publications, 1994.

ORTON Douglas J; WEICK, Karl E. Loosely coupled systems: a reconceptualization. Academy of Management Review,v.15, n.2, p.203-223,1990.

PERROW, C. Institutional school. In: PERROW, C. Complex organizations: a critical essay. New York: McGraw Hill, 1993. p. 157-176.

PHILLIPS,N; LAWERENCE, T.B; HARDY,C. Discourse and institutions. Academy of Management Review, v. 29, n.4, p.635-652, 2004.

REED, M. Teorização organizacional: um campo historicamente contestado. In: CLEGG, S. R. Handbook de estudos organizacionais: modelos de análise e novas questões em estudos organizacionais. São Paulo: Atlas, 1999. p. 61-98. 
Ângela França Versiani, Sérgio Fernando Loureiro Rezende \& Antônio Carlos Pereira

REED, M. The agency/structure dilemma in organization theory: open doors and brick walls. In: TSOUKAS, H.; KNUDSEN, C. The Oxford handbook of organization theory: metatheroretical perspectives. Oxford: Oxford Handbook, 2005. p. 289-309.

REED, M. In praise of duality and dualism: rethinking agency and structure in organizational analysis. Organization Studies, v. 18, n. 1, p. 21-42, 1997.

ROCHA, Maria da Consolação. Políticas de valorização do magistério: remuneração, plano de carreira, condições de trabalho - uma análise da experiência de Belo Horizonte. 2009. 330f. Tese (doutorado). Faculdade de Educação da Universidade de São Paulo, 2009.

ROSSONI, Luciano; GUARIDO FILHO, Edson; CORAIOLA, Diego Maganhoto. Recomendações metodológicas para a adoção da perspectiva da estruturação nos estudos organizacionais. O\&S -Organizações e Sociedade, v.20, n.66, p.523-542, 2013.

ROWAN, B. Organizational structure and the institutional environment: the case of public schools. Administrative Science Quarterly, v. 27, p. 259-279, Jun. 1982.

ROWAN, B.; MISKEL, C. G. Institutional theory and the study of educational organizations. In: MURPHY, J.; LEWIS, K. S. (Ed.). Handbook of research on educational administration. San Francisco: Jossey Bass, 1999.

ROWAN, B.; DENK, C. E. Modeling the academic performance of schools using longitudinal data: an analysis of school effectiveness measures and school and principal effects on school-level performance. San Francisco: Far West Laboratory for Educational Research and Development, 1983.

SCHERER, A. G. Modes of explanation in organization theory. In: TSOUKAS, H.; KNUDSEN, C. The oxford handbook of organization theory: meta-theroretical perspectives. Oxford: Oxford Handbook, 2005. p. 310-344.

SCHLICKMANN, R.; MELO, P. A.; ALPERSTEDT, G. D. Enfoques da teoria institucional nos modelos de avaliação institucional brasileiros. Avaliação, v. 13, n. 1, p. 153-168, 2008.

SCOTT, R. Institutions and organizations. London: Sage Publications, 2001.

SELZNICK, P. Institutionalism "old" and "new". Administrative Science Quarterly, v. 41, n. 2, p. 270-277, 1996.

SECRETARIA MUNICIPAL DE EDUCAÇÃO DE BELO HORIZONTE. Caderno PAP Educação Básica - Escola Plural. Belo Horizonte: SMED, 2003.

SELZNICK, P. Leadership in administration. New York: Harper and Row, 1957.

SELZNICK, P. TVA and the grass roots. Berkeley: University of California Press, 1949.

SILVA, C. L. M.; FONSECA, V. S.; CRUBELLATE, J. M. Estrutura, agência e interpretação: elementos para uma abordagem recursiva do processo de institucionalização. Revista de Administração Contemporânea, v. 14, n. esp., p. 9-39, 2010.

REAd | Porto Alegre - Edição 83 - N 1 - Janeiro/Abril 2016 - p. 193-224 
CONTRIBUIÇÕES DA TEORIA INSTITUCIONAL PARA A ANÁLISE DA GESTÃO DE ESCOLAS: UM ESTUDO DE CASO DE ESCOLA PÚBLICA BRASILEIRA BEM SUCEDIDA NOS ÍNDICES DE DESEMPENHO DA EDUCAÇÃO BÁSICA

SOARES, C. O efeito do lugar e a escolarização de crianças em estabelecimentos públicos. Rio de Janeiro: Observatório das Metrópoles/UFRJ, 2006.

SOARES, J. F. O efeito da escola no desempenho cognitivo de seus alunos. Revista Electrónica Iberoamericana sobre Calidad, Eficacia y Cambio en Educación, v. 2, n. 2, p. 83-104, 2004.

SUDDABY, R. Challenges for institutional theory. Journal of Management Inquiry, v. 19, n. 1, p. 14-20, 2010.

THORNTON, P. H.; OCASIO, W. Institutional logics. In: GREENWOOD, R. The Sage handbook of organizational institutionalism. Londres: SAGE, 2008.

TOLBERT, P.; ZUCKER, L. A institucionalização da teoria institucional. In: CALDAS, M.; FACHIN, R.; FISCHER, T. (Org.). Handbook de estudos organizacionais. São Paulo: Atlas, 1999. p. 196-226.

WEICK, K. Educational Organizations as loosely coupled systems. Administrative Science Quarterly, v. 21, n. 1, p. 1-19, 1976.

WITZIERS, B. Cordination and control in education. In: VISSCHER, A. J. (Org.). Managing schools towards high performance. New York: Taylor \& Francis, 2006. p. 97-134.

YIN, R. K. The case study crisis: some answers. Administrative Science Quartely, v. 26, n. 1, p. 58-65, 1981.

ZILBER, T. B. The work of meanings in institutional processes and thinking. In: GREENWOOD, R. et al. The Sage handbook of organizational institutionalism. London: Sage Publications, 2008.

ZUCKER, L.G. Organizations as institutions. In: BACHARACH, S. (Ed.). Research in the sociology of organizations. Greenwich: JAI Press, 1983. p. 1-47. 